\title{
Variability of Continuously Measured Arterial pH and Blood Gas Values in the Near Term Fetal Lamb
}

\author{
BOUKE R. WOUDSTRA, BEN T. H. M. DE WOLF, TACO M. SMITS, PETER W. NATHANIELSZ, \\ WILLEM G. ZIJLSTRA, AND JAN G. AARNOUDSE \\ Departments of Obstetrics and Gynaecology [B.R.W., B.T.H.M.d.W., T.M.S., J.G.A.] and \\ Physiology[W.G.Z.], University Hospital, Groningen, The Netherlands, and Laboratory for Pregnancy and \\ Newborn Research, Department of Physiology [P.W.N.], New York State College of Veterinary Medicine, \\ Cornell University, Ithaca, New York
}

\begin{abstract}
In fetal sheep, arterial blood gas values show considerable spontaneous fluctuations. The aim of the present study was to obtain quantitative data on fetal blood gas variability. Accurate assessment of the intraindividual variations can hardly be obtained from intermittent blood samples, but requires continuous measurement. For this purpose we developed a small extracorporeal flow-through cuvette, containing $\mathrm{pH}$ and blood gas electrodes and the fiber optic probe of an oximeter. The cuvette is connected through two catheters to the fetal circulation. Blood from the carotid artery flows through the cuvette at a constant rate of $2 \mathrm{~mL} / \mathrm{min}$ and is drained into the jugular vein. Continuous recordings for $6 \mathrm{~h}$ were obtained from five chronically instrumented sheep fetuses at 134-137-d gestational age. Intraindividual variability of fetal arterial blood $\mathrm{pH}(\mathrm{pHa})$, partial pressure of arterial blood $\mathrm{CO}_{2}\left(\mathrm{PaCO}_{2}\right)$ and $\mathrm{O}_{2}\left(\mathrm{PaO}_{2}\right)$, and saturation of arterial blood $\left(\mathrm{SaO}_{2}\right)$ is quantitatively described. The individual
\end{abstract}

variation coefficients ranged from 0.1 to $0.4 \%$ (pHa), from 1.4 to $7.6 \%\left(\mathrm{PaCO}_{2}\right)$, from 2.5 to $5.5 \%\left(\mathrm{PaO}_{2}\right)$, and from 3.6 to $7.0 \%$ $\left(\mathrm{SaO}_{2}\right)$. The 5 th to 95 percentile intervals $(\Delta)$ of the individual blood gas values ranged from 0.03 to 0.09 (pHa), from 0.3 to 1.6 $\mathrm{kPa}\left(\mathrm{PaCO}_{2}\right)$, from 0.22 to $0.5 \mathrm{kPa}\left(\mathrm{PaO}_{2}\right)$, and from 10.5 to $26.0 \%$ $\left(\mathrm{SaO}_{2}\right)$. These findings indicate that considerable fluctuations in fetal arterial blood gases occur during a 6 -h period. These fluctuations are associated with uterine contractures and changes in maternal and fetal activity. (Pediatr Res 38: 528-532, 1995)
pHa, arterial blood $\mathrm{pH}$
Abbreviations
$\mathrm{PaCO}_{2}$, partial pressure of arterial blood $\mathrm{CO}_{2}$
$\mathrm{PaO}_{2}$, partial pressure of arterial blood $\mathrm{O}_{2}$
$\mathrm{SaO}_{2}, \mathrm{O}_{2}$ saturation of arterial blood
EMG, electromyograph

Methods which permit continuous measurement have revealed a considerable variability of arterial blood oxygen tension $\left(\mathrm{PaO}_{2}\right)$ and oxygen saturation $\left(\mathrm{SaO}_{2}\right)$ in the fetal sheep. Changes in fetal oxygenation have been described in relation to uterine contractures, maternal position and fetal activity (1-5). Little is known, however, about corresponding variations in fetal $\mathrm{pHa}$ and $\mathrm{PaCO}_{2}$. In general, hardly any quantitative data on arterial $\mathrm{pH}$ and blood gas variability in the fetus have been reported. Such information is relevant because discrete cord blood samples are increasingly used to assess the condition of the human fetus. We have developed an extracorporeal system with a small dead space to measure $\mathrm{pH}, \mathrm{PCO}_{2}, \mathrm{Po}_{2}$, and $\mathrm{So}_{2}$

Received May 17, 1993; accepted March 27, 1995.

Correspondence and reprint requests: Jan G. Aarnoudse, M.D., Ph.D., Department Obstetrics and Gynaecology, University Hospital, Oostersingel 59, 9713 EZ Groningen, The Netherlands.

Supported in part by a grant from the Ter Meulen Fund of the Royal Dutch Academy of Sciences (to B.R.W.). Glaxo, Nieuwegein, The Netherlands, donated the antibiotics. This study is part of the Research Program on Pregnancy and Early Development. continuously. This system consists of a flow-through cuvette provided with $\mathrm{pH}$ and blood gas electrodes and optical fibers for oximetry. The flow-through cuvette is connected by catheters to an artery and a vein. A constant flow is maintained by a roller pump, out of the artery and into the vein. The aim of the present study was to obtain quantitative data on arterial $\mathrm{pH}$ and blood gas variability over several hours in the chronically instrumented fetal sheep.

\section{METHODS}

Animal preparation. Animal preparation was essentially the same as described previously $(6,7)$. Briefly, pregnant ewes were instrumented on d 120 of gestational age; maternal catheters were inserted into the left femoral artery and vein. Fetal catheters were inserted into the left fetal carotid artery and jugular vein; the orifices of the catheters were placed in or near the arcus aortae and the superior caval vein, respectively. Stainless steel wire electrodes were sewn in the myometrium of 
the ewe. Proximal ends of catheters and electrodes were exteriorized through the flank of the ewe. Experiments were not performed within $12 \mathrm{~d}$ after surgery. Antibiotics (cefuroxime, Zinacef; Glaxo, Nieuwegein, The Netherlands) were used for 5 $\mathrm{d}$ after surgery, twice a day: $1350 \mathrm{mg}$ i.v. maternal, $75 \mathrm{mg}$ i.v. fetal, and $75 \mathrm{mg}$ intraamniotic. All experiments were performed with approval of the local committee on animal care and use.

An initial dosis of 1000 IU heparin was administered into the fetal jugular vein $10 \mathrm{~min}$ before the connection of the fetal catheters to the measuring system. A continuous infusion of heparin $500 \mathrm{IU} / \mathrm{h}$ was maintained during the experiment.

All animals were killed by i.v. injection of thiopental at 145-148 d of gestation, 11-13 d after the experiment.

Flow-through system. The measuring system consists of a flow-through cuvette provided with $\mathrm{pH}$ and blood gas probes, with an afferent and an efferent catheter, connected to the fetal left carotid artery and left jugular vein. A constant flow is maintained by a roller pump. A schematic diagram of the system is given in Fig. 1. The total volume of the system, including the connecting catheters, is $3.25 \mathrm{~mL}$. A roller pump (Heidolph 113.60, L. Eschweiler \& Co., Kiel, Germany) on the afferent catheter is used to maintain a steady flow of blood at $2 \mathrm{~mL} / \mathrm{min}$.

In the cuvette small, commercially available blood gas electrodes $\left(\mathrm{pH}, \mathrm{pH}\right.$ reference, $\mathrm{PCO}_{2}$, and $\mathrm{Po}_{2} ; \mathrm{AVL}$, Vienna, Austria) are fitted, together with optical fibers from an oximeter (IVH3, Schwarzer, Munich, Germany). The signals from the $\mathrm{pH}, \mathrm{PCO}_{2}$, and $\mathrm{Po}_{2}$ electrodes and the output of the oximeter are amplified, filtered, and recorded on an 8-channel polygraph (8802, Gould Inc., Cleveland, OH), as well as analog/digital converted (Lab Tender, Scientific Solutions, Solon, OH) and stored in a microcomputer with a sampling frequency of 0.2 $\mathrm{Hz}$.

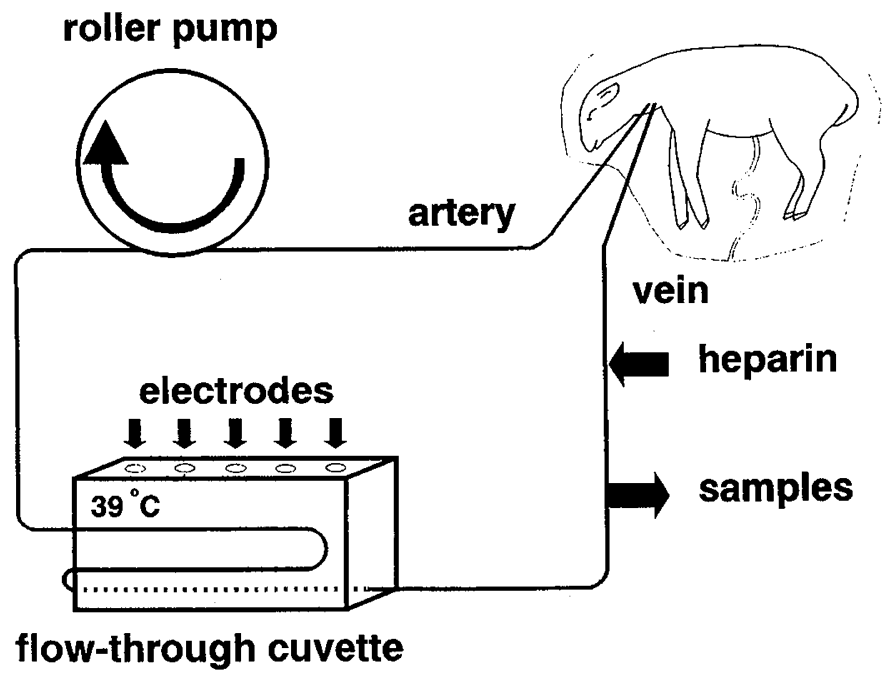

Figure 1. Diagram of the continuous measurement system with the flowthrough cuvette. Blood is drawn from the carotid artery, flows through a roller pump, and is preheated to $39^{\circ} \mathrm{C}$ in a heater loop. The blood flows through the cuvette and is measured by the $\mathrm{pH}, \mathrm{PCO}_{2}$, and $\mathrm{PO}_{2}$ electrodes and the oximeter probe. Next, the blood passes a sampling point and after addition of heparin, reenters the fetus through the jugular vein.
Before each experiment the $\mathrm{PO}_{2}$ and $\mathrm{PCO}_{2}$ electrodes are calibrated with gas mixtures with known volume fractions: $5 \%$ $\mathrm{O}_{2}+5 \% \mathrm{CO}_{2}+90 \% \mathrm{~N}_{2}$ and $10 \% \mathrm{CO}_{2}+90 \% \mathrm{~N}_{2}$. The $\mathrm{pH}$ electrode is calibrated with two phosphate buffers, pH 6.841 and 7.383 (AVL, Graz, Austria). The oximeter is calibrated with the help of a hemoximeter (OSM2, Radiometer, Copenhagen, Denmark) with oxygenated sheep blood. After calibration of the flow-through cuvette the fetus was connected to the system. Arterial blood was pumped from the carotid artery catheter through the cuvette and flowed back into the jugular vein catheter (Fig. 1).

Approximately every $30 \mathrm{~min}$ a blood sample $(0.7 \mathrm{~mL})$ was taken and analyzed immediately on a blood gas analyzer (ABL2 or ABL3, Radiometer) and a hemoximeter (OSM2), to check the readings from the flow-through system. Blood samples were collected when the continuous measurements showed stable values for approximately $1 \mathrm{~min}$.

\section{DATA PROCESSING}

Multiple regression analysis for every single trace is used to assess the quality of the continuous blood gas signals as described previously (6). Linear drift of offset and gain is assumed for all signals. Only recordings with a correlation coefficient $\geq 0.90$ and a significance level $p \leq 0.02$ ( $t$ test for correlation coefficients) are used. Time is not used as an independent variable when it does not contribute to a better correlation. During experiments uterine EMG signals were amplified, filtered (band-pass 0.3-30 Hz), rectified, and, after A/D conversion, sampled at $1 \mathrm{~Hz}$ and stored in a microcomputer. During off-line analysis all events lasting longer than 10 $\mathrm{S}$ and those in which the signal was at least two times the SD plus the average, were considered to be a uterine contracture.

\section{RESULTS}

Figure 2 shows the intra- and interindividual variation of the continuous recordings of $\mathrm{pHa}, \mathrm{PaCO}_{2}, \mathrm{PaO}_{2}$, and $\mathrm{SaO}_{2}$ in five fetuses for a period of $6 \mathrm{~h}$. Uterine contractures are indicated as hatched rectangles. Figure 3 shows the relative frequency distributions of the signals in the total 6-h period.

Table 1 shows quantitative data on intraindividual variability of fetal arterial $\mathrm{pH}$ and blood gas values during the $6 \mathrm{~h}$ of recording the five animals. The results indicate that the individual $\mathrm{pH}$ and blood gas values vary over a wide range. The data also reveal considerable differences in variability between the five fetal sheep.

A striking phenomenon of the continuous recordings is the transient influence of maternal uterine contractures on fetal arterial blood gases. A decrease in $\mathrm{PaO}_{2}, \mathrm{SaO}_{2}$, and $\mathrm{pHa}$ and an increase in $\mathrm{PaCO}_{2}$ is followed after 3-10 min by a return to the precontracture levels. Apart from these relatively short lasting fluctuations associated with contractures, we observed also more sustained changes in blood gas levels, lasting up to $3 \mathrm{~h}$ (sheep 2279, Fig. 2). The continuous recordings further revealed that fetal $\mathrm{pHa}$ and $\mathrm{PaCO}_{2}$ almost always changed in the opposite direction.

Figure $4 A$ represents an example of the changes observed in continuous blood gas measurements when the ewe feeds. The 

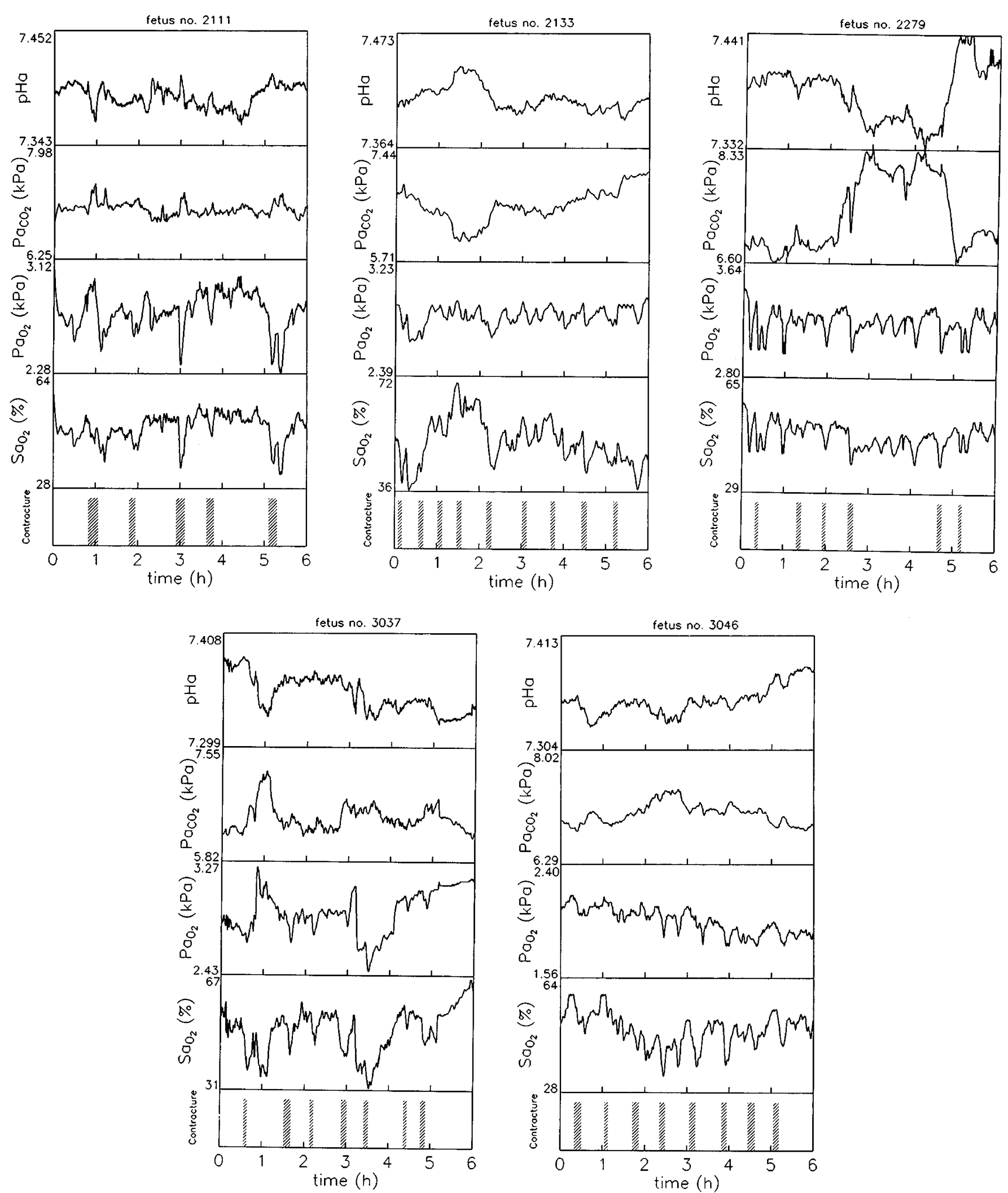

Figure 2. Continuous measurements of atterial blood gas values in 5 fetuses $(A-E)$, each for $6 \mathrm{~h}$; signals of $\mathrm{pHa}, \mathrm{PaCO}_{2}, \mathrm{PaO}_{2}$, SaO ${ }_{2}$, and uterine contractures (computer processed uterine EMG activity) are shown from top to bottom. For each quantity the same calibration of $y$ axis was used in all five experiments.

effect on the fetal blood gases of increased fetal breathing movements, in the absence of uterine contractures, is also demonstrated (Fig. $4 B$ ).
All ewes and fetuses were alive and well with no evidence of major thromboembolic phenomena during the entire 2528-d period after instrumentation. 

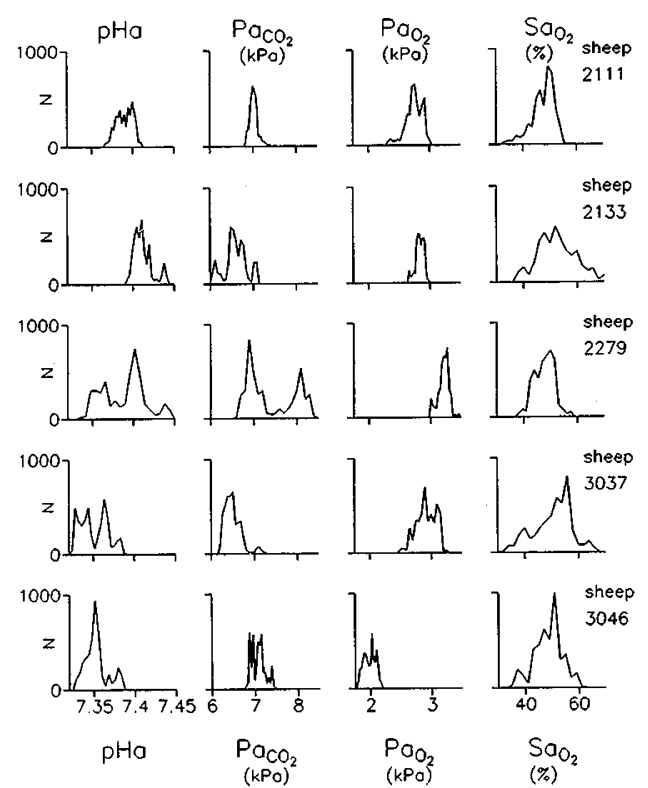

Figure 3. The relative frequency distribution of $\mathrm{pHa}, \mathrm{PaCO}_{2}, \mathrm{PaO}_{2}$, and $\mathrm{SaO}_{2}$, in the five fetal lambs during $6 \mathrm{~h}$ of recording ( $n=$ number of samples).

\section{DISCUSSION}

The fetus depends on the maternal circulation and other transport mechanisms for meeting its oxygen requirements, and for the release of carbon dioxide. Until recently, it was assumed that fetal arterial $\mathrm{pH}$ and blood gas values would not show large fluctuations, because the fetal system is stabilized by the much larger maternal system, and because fetal metabolism was thought to be very constant. However, recent research in the sheep fetus has revealed that $\mathrm{PaO}_{2}$ and $\mathrm{SaO}_{2}$ values vary considerably, even under normal circumstances. These variations are associated with maternal and fetal behavioral changes, such as maternal uterine contractures and fetal movements $(1,2)$. Using a newly developed system for continuous measurements of $\mathrm{pH}$ and blood gases in fetal lambs, we were able to measure subtle and quick alterations in fetal pHa, $\mathrm{PaCO}_{2}$, $\mathrm{PaO}_{2}$, and $\mathrm{SaO}_{2}$. The present study reveals that fetal arterial $\mathrm{pH}$ and blood gas values show considerable "spontaneous" fluctuations. We observed transient changes associated with contracture type myometrial activity, which were superimposed on more sustained changes in blood gas values, lasting up to $3 \mathrm{~h}$. The origin of the sustained changes has to be clarified, but preliminary observations suggest that alterations in maternal activity are relevant in this respect, resulting in changes in maternal ventilation and redistribution of cardiac output of the ewe.

There has been some debate as to how far the physiologic changes in blood gases do have an effect on the fetus. In particular, for oxygen it has been argued that, as long as oxygen consumption is not decreased, a reduction in arterial oxygen concentration has no consequences for the fetus $(8,9)$. There is growing evidence, however, that even relatively small physiologic changes in fetal $\mathrm{PaO}_{2}$ are sensed by the fetus and can stimulate the neuroendocrinologic system. A recent study in the near term sheep fetus showed that plasma ACTH increases as a result of the transient reduction in $\mathrm{PaO}_{2}$ during
Table 1. Minimum (min), maximum (max), average (avg), $S D$, variation coefficient (VC), and 5th, 50th, and 95th percentile (p5-p95) of spontaneous variations in fetal arterial $\mathrm{pH}, \mathrm{PCO}_{2}, \mathrm{PO}_{2}$, and $\mathrm{SO}_{2}$, during a 6-h period of continuous measurement in 5 fetuses

\begin{tabular}{|c|c|c|c|c|c|}
\hline \multirow[b]{2}{*}{ Variations } & \multicolumn{5}{|c|}{ Animal } \\
\hline & 2111 & 2133 & 2279 & 3037 & 3046 \\
\hline \multicolumn{6}{|l|}{ pHa: } \\
\hline $\operatorname{Min}$ & 7.362 & 7.391 & 7.332 & 7.321 & 7.326 \\
\hline Max & 7.412 & 7.442 & 7.441 & 7.385 & 7.383 \\
\hline Avg & 7.39 & 7.411 & 7.386 & 7.35 & 7.351 \\
\hline $\mathrm{SD}$ & 0.01 & 0.011 & 0.026 & 0.017 & 0.013 \\
\hline $\mathrm{VC}(\%)$ & 0.1 & 0.1 & 0.4 & 0.2 & 0.2 \\
\hline $\mathrm{p} 5$ & 7.375 & 7.339 & 7.348 & 7.328 & 7.332 \\
\hline p50 & 7.39 & 7.411 & 7.396 & 7.348 & 7.352 \\
\hline p95 & 7.405 & 7.438 & 7.438 & 7.38 & 7.38 \\
\hline$\Delta(\mathrm{p} 5-\mathrm{p} 95)$ & 0.03 & 0.099 & 0.09 & 0.052 & 0.042 \\
\hline \multicolumn{6}{|l|}{$\mathrm{PaCO}_{2}(\mathrm{kPa}):$} \\
\hline Min & 6.81 & 6.02 & 6.6 & 6.17 & 6.79 \\
\hline $\operatorname{Max}$ & 7.4 & 7.08 & 8.33 & 7.19 & 7.42 \\
\hline Avg & 7.01 & 6.57 & 7.36 & 6.48 & 7.06 \\
\hline $\mathrm{SD}$ & 0.1 & 0.25 & 0.56 & 0.19 & 0.15 \\
\hline $\mathrm{VC}$ & 1.4 & 3.8 & 7.6 & 2.9 & 2.1 \\
\hline p5 & 6.89 & 6.12 & 6.7 & 6.27 & 6.87 \\
\hline p50 & 7.01 & 6.6 & 7.1 & 6.45 & 7.07 \\
\hline p95 & 7.19 & 7.08 & 8.3 & 6.87 & 7.39 \\
\hline$\Delta(\mathrm{p} 5-\mathrm{p} 95)$ & 0.3 & 0.96 & 1.6 & 0.6 & 0.52 \\
\hline \multicolumn{6}{|l|}{$\mathrm{PaO}_{2}(\mathrm{kPa})$} \\
\hline Min & 2.28 & 2.64 & 2.97 & 2.46 & 1.8 \\
\hline $\operatorname{Max}$ & 3.04 & 2.97 & 3.46 & 3.23 & 2.17 \\
\hline Avg & 2.73 & 2.83 & 3.21 & 2.9 & 1.98 \\
\hline SD & 0.14 & 0.07 & 0.09 & 0.16 & 0.09 \\
\hline VC & 5.1 & 2.5 & 2.8 & 5.5 & 4.5 \\
\hline p5 & 2.48 & 2.7 & 3.04 & 2.65 & 1.83 \\
\hline $\mathrm{p} 50$ & 2.76 & 2.84 & 3.22 & 2.9 & 2 \\
\hline p95 & 2.92 & 2.92 & 3.34 & 3.15 & 2.13 \\
\hline$\Delta(\mathrm{p} 5-\mathrm{p} 95)$ & 0.44 & 0.22 & 0.3 & 0.5 & 0.3 \\
\hline \multicolumn{6}{|l|}{$\mathrm{SaO}_{2}(\%):$} \\
\hline Min & 32.3 & 36.2 & 37.5 & 31.6 & 33.1 \\
\hline $\operatorname{Max}$ & 58 & 69.9 & 57.2 & 65.9 & 58.9 \\
\hline Avg & 47 & 51.5 & 47 & 49.7 & 47.6 \\
\hline $\mathrm{SD}$ & 4.3 & 7 & 3.6 & 7 & 5.1 \\
\hline $\mathrm{VC}$ & 9.1 & 13.6 & 7.7 & 14.1 & 10.7 \\
\hline p5 & 39 & 40 & 42.5 & 38 & 37 \\
\hline $\mathrm{p} 50$ & 48 & 52 & 48.5 & 52 & 49 \\
\hline p95 & 54 & 66 & 53 & 62 & 57 \\
\hline$\Delta(\mathrm{p} 5-\mathrm{p} 95)$ & 15 & 26 & 10.5 & 24 & 20 \\
\hline
\end{tabular}

contractures (7). Also several other recent reports indicatie that changes comparable to the spontaneous, physiologic variations we found in arterial blood gases, have an effect on fetal behavior, e.g. nuchal muscle movements, eye movements, fetal breathing movements, and electrocorticographic activity, as well as on endocrine responses $(3,6,7,10-17)$.

In the human fetus, it is practically impossible to measure arterial blood gases continuously. Therefore, human data on variability of arterial blood gas values are not available. Myometrial contractures and changes in maternal and fetal activity, which were associated with the fluctuations in blood gases in the sheep fetus, also occur in human pregnancy. Hence, it is reasonable to assume that similar fluctuations in arterial blood gases exist in the human fetus. If arterial blood gas fluctuations in the human fetus are of the same magnitude as in the sheep 

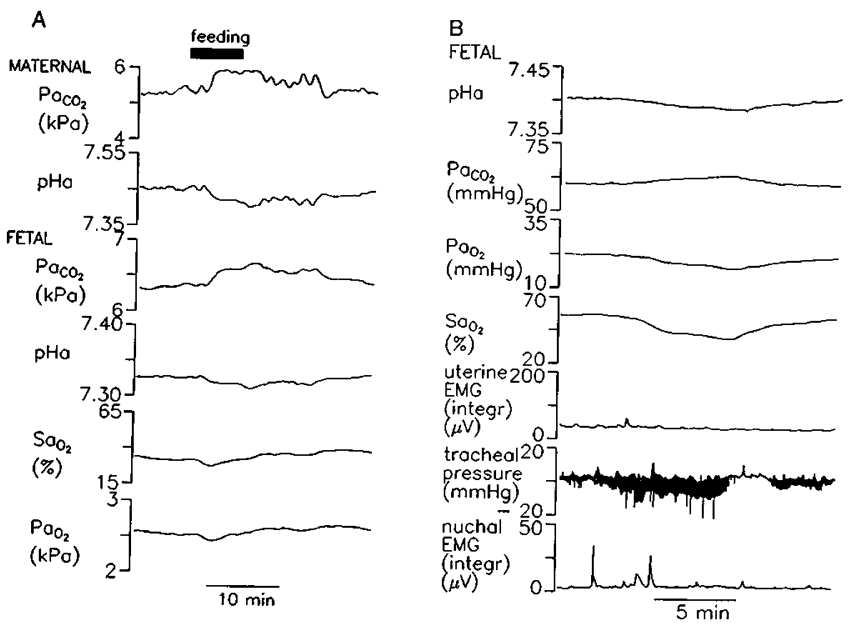

Figure 4. Effect of maternal feeding (black rectangle) on the blood gases in the ewe and the fetus. $(A)$ Shown from top to bottom are maternal $\mathrm{PaCO}_{2}$ and $\mathrm{pHa}$ and fetal $\mathrm{PaCO}_{2}, \mathrm{pHa}, \mathrm{SaO}_{2}$, and $\mathrm{PaO}_{2}$. Maternal arterial blood gases were measured simultaneously with a second flow-through system similar to that used in the fetus; blood was drawn from the abdominal aorta and returned to the femoral vein. Changes in fetal blood gases during fetal breathing movements, in the absence of uterine contractures $(B)$. Shown from top to bottom are fetal $\mathrm{pHa}, \mathrm{PaCO}_{2}, \mathrm{PaO}_{2}$, and $\mathrm{SaO}_{2}$, maternal uterine EMG activity, and fetal tracheal pressure and nuchal muscle EMG activity.

fetus, the clinical usefulness of a single blood sample obtained by cordocentesis is limited with respect to $\mathrm{pH}$ and blood gas values.

Acknowledgments. The authors thank Jetty Veendijk for assistance in the preparation of this manuscript. A major contribution to the work presented here has been made by Xiu-Ying Ding, Richard Wentworth, Charles Mecenas, Luce Guanzini, Jan Elstrodt, and Albert Polman.

\section{REFERENCES}

1. Jansen CAM, Krane EJ, Thomas AL, Beck NFG, Lowe KC, Joyce P, Parr M, Nathanielsz PW 1979 Continuous variability of fetal $\mathrm{Po}_{2}$ in the chronically catheterized fetal sheep. Am J Obstet Gynecol 134:776-783

2. Harding R, Sigger JN, Wickham PJD 1983 Fetal and maternal influences on arterial oxygen levels in the sheep fetus. J Dev Physiol 5:267-276

3. Walker AM, Fleming J, Smolich J, Stunden R, Horne R, Maloney J 1984 Fetal oxygen consumption, umbilical circulation and electrocortical activity transitions in fetal lambs. J Dev Physiol 6:267-274

4. Calabum T, Nathanielsz PW 1981 The effect of episodes of tonic myometrial activity on common uterine artery blood flow in the pregnant sheep at 110 to 135 days gestation. J Physiol 320:104P-105P

5. Hofmeyr GJ, Bamford OS, Gianopoulos JG, Parkes MJ, Dawes GS 1985 The partial association of uterine contractions with changes in electrocortical activity, breathing and $\mathrm{PaO}_{2}$ in the fetal lamb: effects of brain stem section. Am J Obstet Gynecol 152:905-910

6. Woudstra BR, Aarnoudse JG, de Wolf BTHM, Zijlstra WG 1990 Nuchal muscle activity at different levels of hypoxemia in fetal sheep. Am J Obstet Gynaecol 162:559-564

7. Woudstra BR, Kim C, Aarnoudse JG, Nathanielsz PW 1991 Myometrial contracture related increase in plasma $\mathrm{ACTH}$ in fetal sheep in the last trimester of gestation are abolished by maintaining fetal normoxemia. Endocrinology 129:1709-1713

8. Clapp JF 1978 The relationship between blood flow and oxygen uptake in the uterine and umbilical circulations. Am J Obstet Gynecol 132:410-413

9. Longo LD, Hill EP, Power GG 1972 Theoretical analysis of factors affecting placental $\mathrm{O}_{2}$ transfer. Am J Physiol 222:730-739

10. Harding R, Poore ER, Cohen GL 1981 The effect of brief episodes of diminished uterine blood flow on breathing movements, sleep states and heart rate in fetal sheep. J Dev Physiol 3:231-243

11. Jones CT 1977 The development of some metabolic responses to hypoxia in the foetal sheep. J Physiol 265:743-62

12. Cohen WR, Piasecki GJ, Cohn HE, Susa JB, Jackson BT 1991 Sympathoadrenal responses during hypoglycemia, hyperinsulinemia, and hypoxemia in the ovine fetus. Am J Physiol 261:E95-E102

13. Raff H, Kane CW, Wood CE 1991 Arginine vasopressin responses to hypoxia and hypercapnia in late-gestation fetal sheep. Am J Physiol 260:R1077-R1081

14. Paulick RP, Meyers RL, Rudolph CD, Rudolph AM 1990 Venous responses to hypoxemia in the fetal lamb. J Dev Physiol 14:81-88

15. Akagi K, Challis JR 1990 Hormonal and biophysical responses to acute hypoxemia in fetal sheep at 0.7-0.8 gestation. Can J Physiol Pharmacol 68:1527-1532

16. Bamford OS, Dawes GS 1990 Hypoxia and electrocortical activity in the fetal lamb: effects of brainstem transection and chemoreceptor denervation. J Dev Physiol 13:271-276

17. Akagi K, Challis JR 1990 Relationship between blood gas values and hormonal response to acute hypoxemia in fetal sheep. Gynecol Obstet Invest 30:65-70 